\title{
Generación de radicales libres por efecto de vitamina C sobre un jarabe antianémico de sulfato ferroso
}

\author{
Henry Guija-Guerra ${ }^{1}$, Emilio Guija-Poma ${ }^{1}$, John Ponce-Pardo ${ }^{1}$, Miguel Inocente-Camones ${ }^{1}$, Luis Camarena-Chaviguri ${ }^{1}$
}

\author{
RESUMEN
}

Objetivo: Determinar el efecto que ejerce la vitamina C sobre el sulfato ferroso, principio activo de un jarabe antianémico. Materiales y métodos: La reacción que se produce entre el sulfato ferroso de un jarabe antianémico y la vitamina $C$ se determinó al aplicar la técnica de descomposición de la desoxirribosa, que evalúa la formación de malondialdehído por acción de radicales libres.

Resultados: En un medio de ensayo constituido por tampón fosfato $50 \mathrm{mM}(\mathrm{pH} 7,4)$, el jarabe antianémico de sulfato ferroso a una concentración $1,080 \mathrm{mM}$ reaccionó con la vitamina $C$ en concentraciones comprendidas entre $5,0 \times 10^{-6} \mathrm{mM}$ y $0,5 \mathrm{mM}$, generando radicales libres que disminuyen cuando se utiliza una concentración de vitamina $C$ de $5,0 \times 10^{-2} \mathrm{mM}$ mientras que a una concentración $0,5 \mathrm{mM}$, se eleva. Cuando se usa sulfato ferroso en condiciones similares se aprecia un incremento de la generación de radicales libres que alcanza un valor máximo a una concentración de vitamina $C$ de 5,0 $x 10^{-6} \mathrm{mM}$ que se mantiene invariable a concentraciones de dos órdenes de magnitud mayor y, ulteriormente, decrece a concentraciones más elevadas. La vitamina $C$ a una concentración 1,0 mM reacciona con el sulfato ferroso utilizado en concentraciones comprendidas entre 0,270 y 2,160 mM describiendo una curva de tipo hiperbólica. En cambio, el jarabe de sulfato ferroso, utilizado en las mismas concentraciones, mostró un elevado incremento a bajas concentraciones de tipo no lineal pero que tuvo una respuesta lineal a partir de la concentración 0,540 mM del jarabe, respuesta que fue mayor a la alcanzada por el sulfato ferroso disuelto en agua destilada.

Conclusiones: La vitamina $C$ reacciona con el jarabe de sulfato ferroso y genera radicales libres, esta respuesta depende de las concentraciones relativas de sulfato ferroso, vitamina $\mathrm{C}$ y de los excipientes del jarabe.

Palabras clave: Sulfato ferroso; Vitamina C; Anemia; Radicales libres (Fuente: DeCS BIREME).

\section{Generation of free radicals by the effect of vitamin C on a ferrous sulfate antianemic syrup}

ABSTRACT

Objective: To determine the effect of vitamin $\mathrm{C}$ on ferrous sulfate, the active ingredient of an antianemic syrup.

Materials and methods: The reaction between the ferrous sulfate contained in an antianemic syrup and vitamin $C$ was determined using the decomposition technique of deoxyribose, which evaluates the formation of malondialdehyde by the action of free radicals.

Results: In an assay medium consisting of $50 \mathrm{mM}$ phosphate buffer $(\mathrm{pH} 7.4)$, the ferrous sulfate antianemic syrup at a concentration of $1.080 \mathrm{mM}$ reacted with vitamin $C$ at concentrations between $5.0 \times 10^{-6} \mathrm{mM}$ and $0.5 \mathrm{mM}$, generating levels of free radicals that decrease when vitamin $C$ is used at a concentration of $5.0 \times 10^{-2} \mathrm{mM}$, and increase at a concentration of $0.5 \mathrm{mM}$. When ferrous sulfate is used under similar conditions, an increase in the generation of free radicals is observed, which reaches a maximum value with vitamin $C$ at a concentration of $5.0 \times 10^{-6} \mathrm{mM}$, remains unchanged at concentrations of two orders of magnitude higher, and subsequently decreases at higher concentrations. Vitamin $C$ at a concentration of $1.0 \mathrm{mM}$ reacts with ferrous sulfate used at concentrations between 0.270 and $2.160 \mathrm{mM}$, describing a hyperbolic curve. In contrast, ferrous sulfate syrup used at the same concentrations showed a high increase at low non-linear concentrations, but a linear response from the $0.540 \mathrm{mM}$ concentration of the syrup, a response that was higher than that reached by the ferrous sulfate dissolved in distilled water.

Conclusions: Vitamin $C$ reacts with ferrous sulfate syrup generating free radicals. This response depends on the relative concentrations of ferrous sulfate, vitamin $C$ and syrup excipients.

Keywords: Ferrous sulfate; Vitamin C; Anemia; Free radicals (Source: MeSH NLM).

1. Universidad de San Martín de Porres, Facultad de Medicina Humana, Instituto de Investigación, Centro de Investigación de Bioquímica y Nutrición. Lima, Perú. 


\section{INTRODUCCIÓN}

La anemia ferropénica es una enfermedad de elevada prevalencia en nuestro país, la Encuesta Demográfica y de Salud Familiar de 2016 refiere que el 33,3 \% de los niños menores de cinco años de edad padecen de esta enfermedad (1) y un aspecto preocupante es que los efectos adversos de la anemia son irreversibles. El tratamiento de esta enfermedad consiste en la administración de sulfato ferroso, ya sea en polvo con los alimentos, en gotas o como jarabe, con la indicación adicional de que el paciente ingiera bebidas preparadas con frutas cítricas como el limón o la naranja, para aprovechar el contenido de vitamina $C$ de estos alimentos, con el propósito de incrementar la eficiencia de la absorción del hierro a nivel intestinal ${ }^{(2)}$.

La vitamina $C$ cumple múltiples funciones en el organismo como la de participar en la síntesis de colágeno, proceso de cicatrización, síntesis de catecolaminas, síntesis de carnitina, etc.; así como la de modular el metabolismo del hierro estimulando la síntesis de ferritina, inhibiendo la degradación lisosomal de ferritina y disminuyendo el flujo celular del hierro ${ }^{(3)}$. Otra de las características de esta vitamina es comportarse como un eficiente reductor $y$, en consecuencia, tener una elevada capacidad antioxidante, es decir, la propiedad de bloquear la acción dañina de los radicales libres. Pero también se han descrito situaciones en que se comporta como un peligroso compuesto prooxidante, ya que en determinadas condiciones fisiológicas puede generar radicales libres; en tal sentido, se ha observado que la vitamina $\mathrm{C}$ tiene la propiedad de reaccionar con metales de transición como el cobre y fierro, a través de un proceso que comprende la formación de compuestos intermedios los que, posteriormente, conducen a la formación de radicales hidroxilos (4) que son moléculas de elevada reactividad conforme lo refiere su vida media que es aproximadamente $1 \times 10^{-9}$ segundos; es decir, participa en reacciones controladas por difusión y tienen la propiedad de dañar proteínas, lípidos y ácidos nucleicos ${ }^{(5)}$.

Cuando la generación de radicales libres supera la capacidad del sistema antioxidante en el ser humano lo conduce al estrés oxidativo, condición que es causante de ciertas enfermedades como la psoriasis o que está presente en un gran número de patologías como el cáncer, diabetes mellitus, aterosclerosis, (5-7) etc. El ser humano dispone de un sistema antioxidante constituido por sustancias de naturaleza enzimática y no enzimática, pero cuya eficiencia con frecuencia es superada por compuestos generadores de radicales libres, situación que lo conduce al estrés oxidativo. Con la finalidad de evitar la acción nociva de los radicales libres es necesario ingerir frutas y verduras que tengan elevada acción antioxidante ${ }^{(8)}$, gracias a su contenido en polifenoles, antocianinas, vitamina $\mathrm{C}$, flavonoides, B-caroteno, licopeno, etc.

La administración de jarabe de sulfato ferroso con la posterior ingesta de una fuente de vitamina $C$ puede tornar a esta asociación muy dañina para las personas que lo ingieran ${ }^{(9)}$, ya que el ion ferroso puede reaccionar con la vitamina $\mathrm{C}$ y formar radical hidroxilo y, adicionalmente, existe la posibilidad de que los excipientes del jarabe puedan modificar la naturaleza de esta reacción. En el presente trabajo mostramos que cuando reaccionan los componentes de un jarabe de sulfato ferroso con vitamina $C$ se generan radicales libres, efecto que es dependiente de las concentraciones relativas de ambos reaccionantes, así como de los excipientes del jarabe.

\section{MATERIALES Y MÉTODOS}

Los reactivos químicos ácido tiobarbitúrico, fosfato de potasio monobásico, vitamina $\mathrm{C}$ y ácido tricloroacético fueron de Merck Darmstadt, la 2-desoxirribosa se adquirió de Sigma Chemical Co. El jarabe comercial de sulfato ferroso fue el que se utiliza para el tratamiento de la anemia ferropénica. Todos los reactivos químicos fueron de grado analítico.

\section{Descomposición de la desoxirribosa}

Esta técnica, propuesta por Gutteridge ${ }^{(10)}$, se utiliza para determinar en un medio de ensayo la presencia de radicales hidroxilo o "especies reactivas al ácido tiobarbitúrico" (TBARS por sus siglas en inglés), los que tienen la propiedad de escindir la 2-desoxirribosa y convertirla en malondialdehído, compuesto que reacciona con el ácido tiobarbitúrico y forma una sustancia que absorbe a $532 \mathrm{~nm}$.

El medio de ensayo en un volumen final de $2,0 \mathrm{~mL}$ estuvo constituido básicamente por $1,0 \mathrm{~mL}$ de tampón fosfato

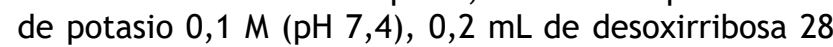
$\mathrm{mM}$, un volumen conocido de una solución acuosa de sulfato ferroso o del jarabe de sulfato ferroso y un volumen definido de una solución de concentración conocida de vitamina $\mathrm{C}$. Se llevó al baño maría a $37{ }^{\circ} \mathrm{C}$ durante 30 minutos y luego se añadió $1,0 \mathrm{~mL}$ de ácido tricloroacético al $10 \%$ y $1,0 \mathrm{~mL}$ de ácido tiobarbitúrico al 0,6\%. 
Se sometió a ebullición durante 15 minutos, a cuyo término se enfriaron los tubos que estuvieron premunidos de una tapa rosca. Las lecturas de la absorbancia se realizaron en un espectrofotómetro Hewlett Packard modelo Lambda 25 a una longitud de onda de $532 \mathrm{~nm}$. Paralelamente, se preparó el blanco correspondiente. Para realizar los cálculos cuantitativos se utilizó un coeficiente de extinción molar ${ }^{(11)}$ de $1,56 \times 10^{5} \mathrm{M}^{-1} \mathrm{~cm}^{-1}$. Todas las determinaciones se realizaron por triplicado.

\section{RESULTADOS}

Cuando el sulfato ferroso y la vitamina $C$ se encuentran en un medio de ensayo constituido por tampón fosfato $50 \mathrm{mM}(\mathrm{pH} \mathrm{7,4)}$ y desoxirribosa $2,8 \mathrm{mM}$, reaccionan a través de un proceso que es dependiente de las concentraciones relativas de ambos compuestos, con la consiguiente formación de especies reactivas al ácido tiobarbitúrico (TBARS). Para las determinaciones analíticas se utilizó un jarabe comercial que en $100 \mathrm{~mL}$ tenía disuelto $1500 \mathrm{mg}$ de sulfato ferroso; este medicamento se utiliza actualmente para el tratamiento de la anemia ferropénica en el Perú. La concentración de vitamina $C$ en el medio de ensayo fue 1,0 mM, compuesto que reaccionó con volúmenes variables del jarabe cuya concentración de sulfato ferroso estuvo comprendida entre $0,270 \mathrm{mM}$ y $2,160 \mathrm{mM}$.

La reacción de ambos compuestos permite observar un incremento inicial elevado de la formación de TBARS cuyo valor fue de 9,64 nmoles, que se obtuvo cuando la concentración de sulfato ferroso del jarabe fue 0,270 $\mathrm{mM}$, mientras que con la concentración $0,540 \mathrm{mM}$ que debería corresponder al doble de TBARS, solamente se observa un valor de 10,64 nmoles conforme se aprecia en la figura 1, pero a partir de esta concentración el incremento de la generación de TBARS se produce de una manera lineal hasta alcanzar la formación de 22,84 nmoles de TBARS, que corresponde a una concentración de sulfato ferroso del jarabe de 2,160 mM.

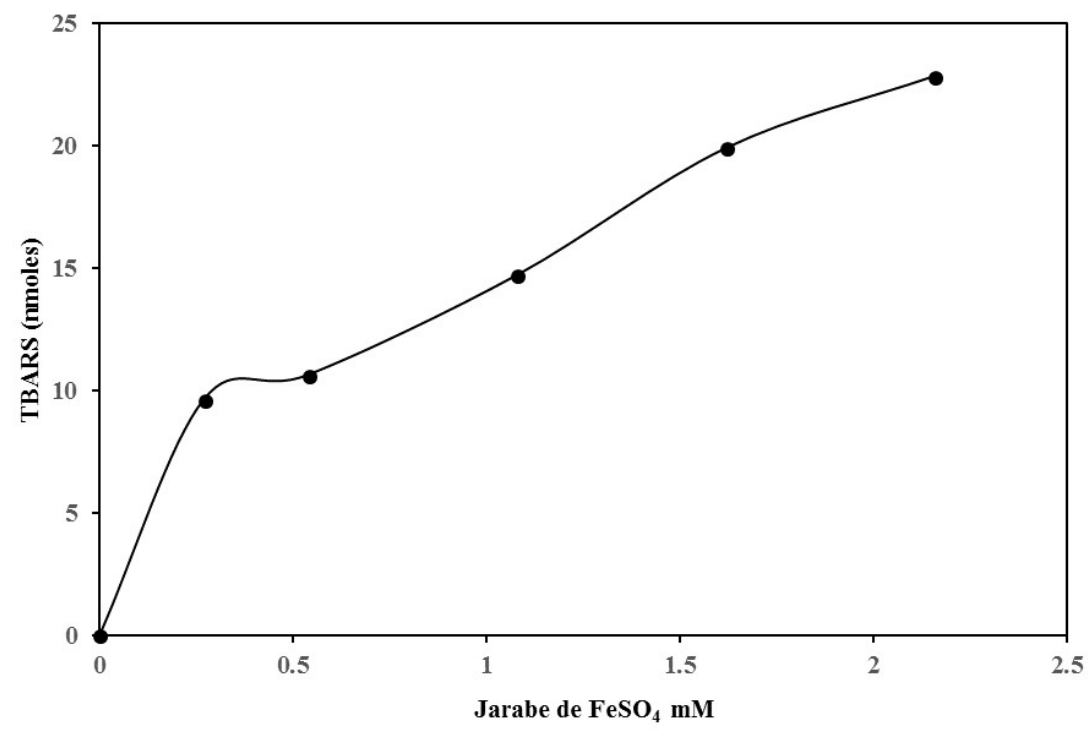

Figura 1. Generación de TBARS por la reacción de diferentes concentraciones de jarabe de sulfato ferroso con ácido ascórbico 1,0 mM, en un medio de ensayo constituido por tampón fosfato $50 \mathrm{mM}(\mathrm{pH} 7,4)$

Bajo las mismas condiciones experimentales descritas anteriormente de tampón fosfato $50 \mathrm{mM} \quad(\mathrm{pH}$ 7,4 ), desoxirribosa $2,8 \mathrm{mM}$ y vitamina $C 1,0 \mathrm{mM}$, se puede observar que utilizando soluciones acuosas de sulfato ferroso en concentraciones iguales a las descritas para el jarabe, es decir, en el rango 0,270 mM y 2,160 mM, el incremento de la formación de TBARS es de naturaleza hiperbólica, curva caracterizada por mostrar un valor máximo de 7,67 nmoles cuando la concentración de sulfato ferroso es $1,080 \mathrm{mM}$, esta formación de TBARS decrece ligeramente a medida que se incrementa la concentración de sulfato ferroso de $1,618 \mathrm{mM}$ a 2,160 mM (Figura 2). 


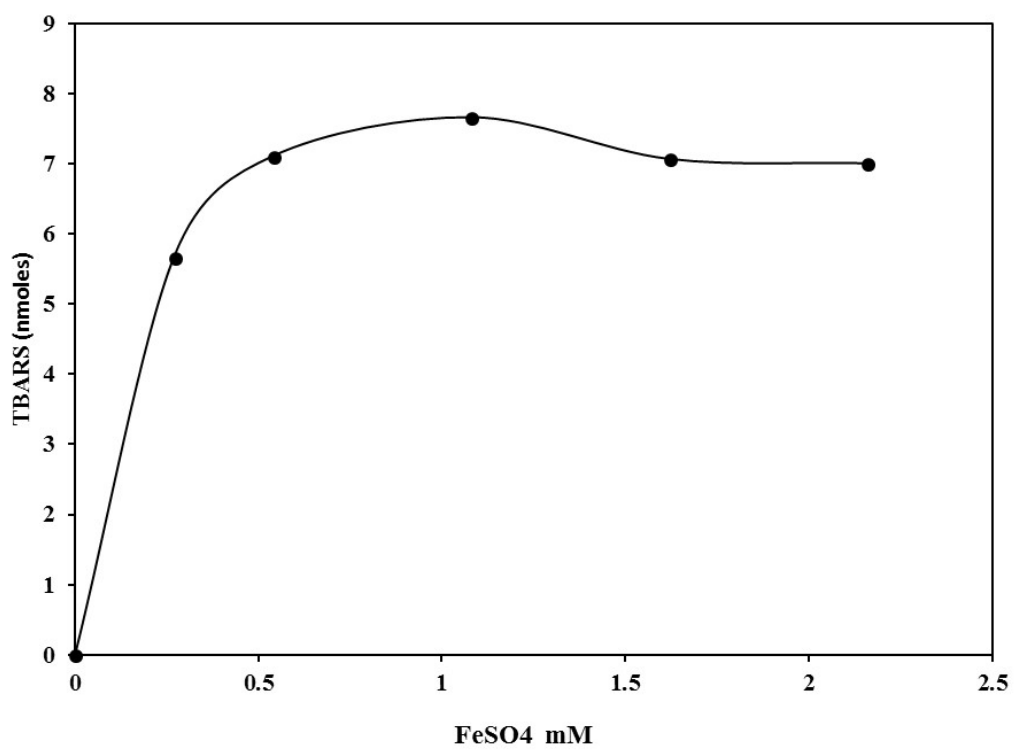

Figura 2. Formación de TBARS generados por la reacción de sulfato ferroso con una concentración 1,0 mM de vitamina C, en un medio de ensayo constituido por tampón fosfato $50 \mathrm{mM}(\mathrm{pH} \mathrm{7,4)}$

Con el propósito de observar el comportamiento de la vitamina $\mathrm{C}$ frente al jarabe de sulfato ferroso, se preparó un medio de ensayo cuya concentración de la sal de fierro fue $1,080 \mathrm{mM}$, mientras que la vitamina $C$ estuvo presente en concentraciones en un rango comprendido entre $5,0 \times 10^{-6} \mathrm{mM}$ y $0,5 \mathrm{mM}$. En la figura 3 se observa un considerable incremento en la formación de TBARS cuando la concentración de vitamina $C$ fue de $5,0 \times 10^{-6}$ $\mathrm{mM}$, aumento que prácticamente no se modifica cuando las concentraciones de vitamina $C$ se elevan a $5,0 \times 10^{-4} \mathrm{mM}$, es decir, concentraciones con una diferencia de dos órdenes de magnitud; en cambio, cuando la concentración de la vitamina $C$ en el medio de ensayo se elevó a valores de $5,0 \times 10^{-3} \mathrm{mM}$ y $5,0 \times 10^{-2} \mathrm{mM}$ se observa una disminución perceptible de la generación de TBARS: 14,38 y 14,31 nmoles, que posteriormente se eleva a un valor de 17,53 nmoles cuando se utiliza una concentración de vitamina $C$ de $0,5 \mathrm{mM}$, elevación que fue ligeramente mayor a aquella en que esta vitamina estuvo presente en el medio de reacción a una concentración 5,0 × 10-6 $\mathrm{mM}$.

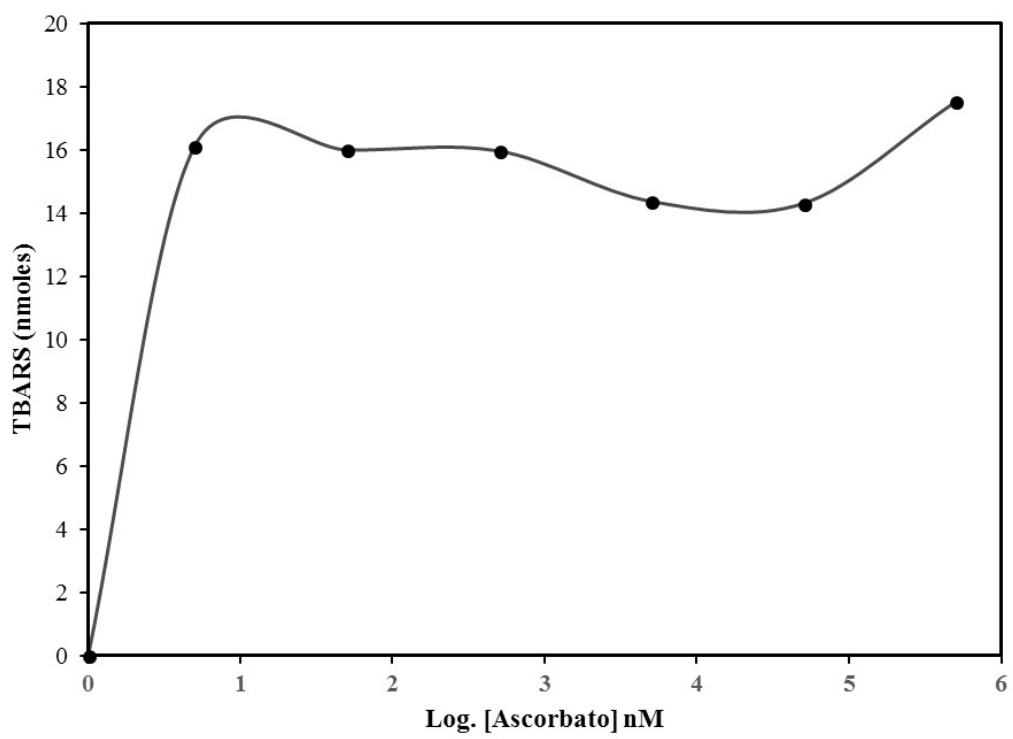

Figura 3. Efecto de la concentración de vitamina $\mathrm{C}$ en la generación de TBARS en presencia de jarabe de sulfato ferroso 1,080 mM. El medio de ensayo estuvo constituido por tampón fosfato $50 \mathrm{mM}(\mathrm{pH} \mathrm{7,4)}$ 
Una situación análoga se puede observar en el ensayo realizado con sulfato ferroso, donde las concentraciones de hierro eran iguales a la del jarabe de sulfato ferroso descrito anteriormente, es decir, $1,080 \mathrm{mM}$, mientras que la concentración de vitamina $C$ estuvo comprendida entre $5,0 \times 10^{-6} \mathrm{mM}$ y $0,5 \mathrm{mM}$. Conforme se observa en la figura 4 , donde se grafica la formación de TBARS en función del logaritmo de la concentración $\mathrm{nM}$ de vitamina $\mathrm{C}$, ocurre un elevado incremento inicial de TBARS cuyo valor fue de 39,94 nmoles que corresponde a una concentración 5,0 x 10-6 mM de vitamina $C$, esta elevación se mantuvo prácticamente invariable a una concentración 100 veces mayor de esta vitamina, es decir, 5,0 x 10-4 $\mathrm{mM}$ cuya formación de TBARS fue 39,97 nmoles, pero decrece en presencia de mayores concentraciones de esta vitamina, alcanzando un valor notablemente menor de 10,70 nmoles cuando la vitamina $C$ estuvo presente en una concentración de tres órdenes de magnitud mayor, o sea $0,5 \mathrm{mM}$; este resultado puede apreciarse en la figura 4.

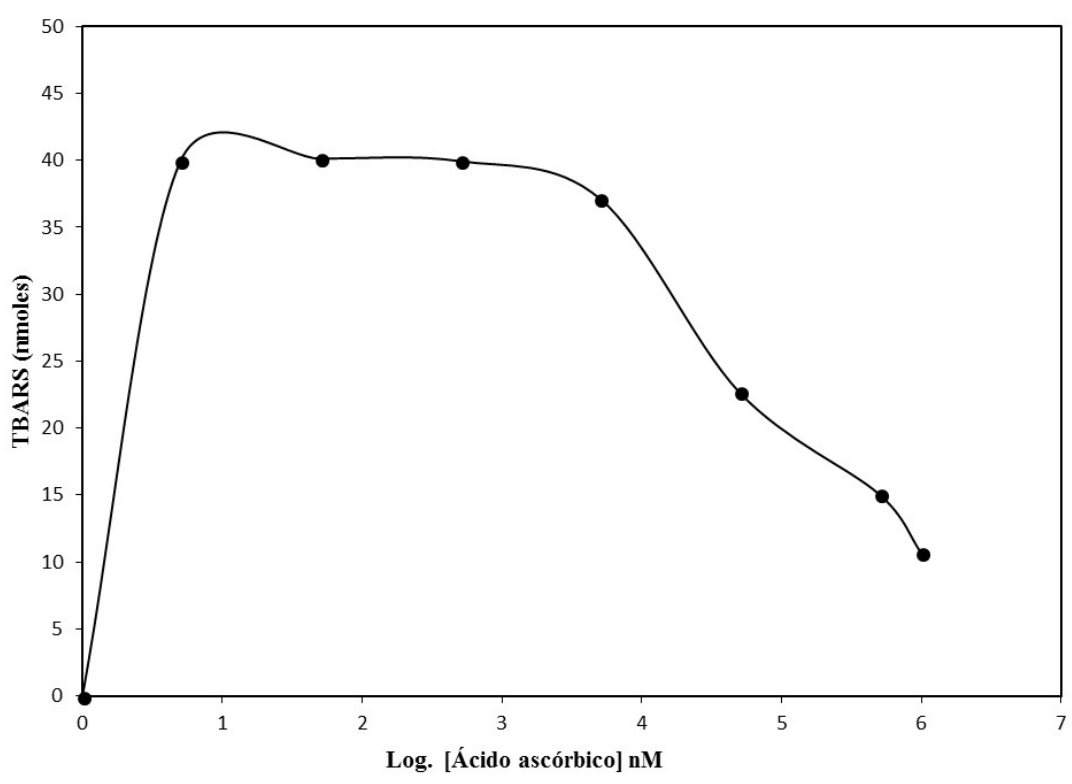

Figura 4. Efecto de la concentración de vitamina $C$ en la generación de TBARS en presencia de sulfato ferroso 1,080 mM. El medio de ensayo estuvo constituido por tampón fosfato $50 \mathrm{mM}(\mathrm{pH} 7,4)$

\section{DISCUSIÓN}

Moses Gomberg ${ }^{(12)}$ en 1900 propuso la existencia del radical libre trifenilmetilo, posteriormente Gerschman (13) intentó explicar en 1954 la toxicidad del oxígeno en animales de experimentación, que murieron después de haber sido expuestos durante tres días en un ambiente de oxígeno puro; pero en aquella época era inaceptable una explicación que considerara la reducción univalente del oxígeno. Posteriormente, Harman ${ }^{(14)}$ en 1956 propuso la "Teoría de los radicales libres del envejecimiento" que actualmente es el planteamiento que ha recibido mayor aceptación. Por lo cual, cuando Mc Cord y Fridovich (15) describieron en 1969 la existencia de la enzima superóxido dismutasa, se aceptó que la generación del radical anión superóxido ocurría en la cadena respiratoria mitocondrial, y desde entonces, se han descrito un gran número de estudios muy bien documentados de la estrecha relación que existe entre los radicales libres y un gran número de condiciones patológicas.

El hierro es un elemento que el ser humano debe ingerir necesariamente en su dieta, absorbiéndose a nivel intestinal (2), con una eficiencia que depende del tipo de hierro ingerido, es decir, ya sea que se encuentre como hierro hemo o bajo la forma de hierro no hemo; posteriormente, es trasportado en la sangre por la transferrina y se almacena ligado a la ferritina en la célula. Este metal cumple diversas funciones en el organismo (16). Cuando se une a los citocromos tiene la propiedad de interconvertirse de su forma ferrosa $\left(\mathrm{Fe}^{2+}\right)$ a la forma férrica $\left(\mathrm{Fe}^{3+}\right)$, proceso que ocurre principalmente en el transporte de electrones mitocondrial. El ion ferroso tiene la propiedad de reaccionar con el peróxido de hidrógeno 
oxidándose a la forma férrica $\left(\mathrm{Fe}^{3+}\right)$ y generando, al mismo tiempo el radical hidroxilo $\left(\mathrm{OH}^{-}\right)$, radical que reacciona muy rápidamente con proteínas, lípidos y ácidos nucleicos a través de una reacción controlada por difusión ${ }^{(6)}$.

La generación de radicales libres en el ser humano se realiza de manera muy diversa; uno de los sitios en que se forman es la cadena respiratoria mitocondrial, donde el oxígeno es reducido de manera univalente por los complejos respiratorios I y III, formando el anión superóxido; este radical sufre un proceso de dismutación por acción de la superóxido dismutasa originando el peróxido de hidrógeno, compuesto que fácilmente puede difundir de la mitocondria al citosol o puede ser descompuesto por acción de la catalasa ${ }^{44,5)}$. También se generan radicales libres por acción de la NADPH oxidasa, a través de la reacción del peróxido de hidrógeno con metales de transición, por acción catalítica de la xantina oxidasa en los procesos de isquemia y reperfusión, por la reacción entre la vitamina $C$ con metales de transición como el ion cuproso o el ion ferroso, etc.

El ser humano dispone de un sistema antioxidante constituido por enzimas y compuestos no enzimáticos que impediría la instauración del estrés oxidativo, pero este sistema antioxidante no es lo suficientemente eficiente, por lo que es necesario que ingiera compuestos con propiedades antioxidantes, los que se encuentran en alimentos como las frutas y verduras ${ }^{(5)}$.

Se ha descrito que la vitamina $C$ reacciona con metales de transición como el hierro y cobre y genera el radical hidroxilo que es el radical libre más nocivo para el ser humano ${ }^{(5,17)}$; por lo tanto, cuando un paciente anémico ingiere un jarabe de sulfato ferroso y posteriormente, un jugo de naranja o una limonada, bebidas que son fuente de vitamina $C$ cuya ingesta se recomienda para propiciar una mejor absorción del hierro, se estarían dando las condiciones necesarias para que la vitamina $C$ reaccione con el hierro del sulfato ferroso y genere radicales libres. Estos radicales libres ejercerían un efecto nocivo a nivel gastrointestinal y ulteriormente, podrían dañar el hígado y otros tejidos.

Cuando se comparan los resultados experimentales obtenidos bajo similares condiciones de ensayo del jarabe de sulfato ferroso y la solución acuosa de sulfato ferroso, es decir, aquella en que la concentración de vitamina $C$ en el medio de ensayo era $1.0 \mathrm{mM}$, el incremento de la concentración de sulfato ferroso describe una curva de tipo hiperbólica, observación que no se produjo cuando se utilizó el jarabe de sulfato ferroso, este resultado estaría sugiriendo que los excipientes del jarabe participarían en la reacción antes descrita ya que las concentraciones de sulfato ferroso en ambas condiciones experimentales eran iguales.
El ion ferroso tiene la propiedad de reaccionar con el oxígeno formando el anión superóxido, compuesto que a través de una reacción de dismutación forma peróxido de hidrógeno, este último compuesto interacciona con el ion ferroso generando ion férrico y radical hidroxilo. La presencia de ascorbato permite reducir el ion férrico a ion ferroso, por lo que el efecto del ascorbato in vivo dependerá de la acción catalítica de los metales de transición (17). Nuestros resultados experimentales muestran que las reacciones antes descritas estarían produciéndose cuando el jarabe de sulfato ferroso reacciona con la vitamina C.

En una observación realizada en mitocondria de hígado de rata tratada con ascorbato y sulfato ferroso pudo percibirse que los fosfolípidos sufrieron procesos de lipoperoxidación, que corresponde al ácido araquidónico de la fosfatidil colina y la fosfatidil etanolamina, los que decrecieron $39 \%$ y $41 \%$ respectivamente, lo que indica que el ácido araquidónico de los fosfolípidos de la membrana mitocondrial sirvieron como sustrato preferencial para la reacción de peroxidación ${ }^{(18)}$, observación que pone de manifiesto que este proceso estaría vinculado con la acumulación de vitamina $\mathrm{C}$ y ion ferroso en el hígado. Estos resultados señalan la activa participación de los radicales libres en las reacciones de peroxidación lipídica, sugiriendo el probable efecto que podría ejercer la ingesta del jarabe de sulfato ferroso con la vitamina $C$ contenida en los jugos de frutas cítricas.

La generación de radicales libres que ocurre cuando reacciona la solución acuosa de sulfato ferroso o el jarabe de sulfato ferroso a una concentración $1,080 \mathrm{mM}$, con diferentes concentraciones de vitamina $C$, produce una respuesta que fue dependiente del tipo de disolución del sulfato ferroso; es decir, cuando se utiliza sulfato ferroso disuelto en agua destilada se obtiene una curva de tipo hiperbólica, en cambio, el uso del jarabe de sulfato ferroso bajo las mismas condiciones experimentales permite observar una recta paralela al eje de abscisas. Estos comportamientos completamente distintos del sulfato ferroso en medio acuoso y aquel que se encuentra como principio activo del jarabe, sugiere que los excipientes de la forma farmacéutica estarían participando en la reacción antes descrita.

Diversas evidencias señalan que la cosuplementación de sales ferrosas con vitamina $C$ incrementa el estrés oxidativo en el tracto gastrointestinal, que podría haber sido causado por especies reactivas de oxígeno y nitrógeno. La vitamina C tiene la capacidad de ejercer un efecto prooxidante mediante su interacción con metales de transición como el cobre y hierro. En una investigación realizada con madres gestantes a quienes se les administró $100 \mathrm{mg}$ de hierro y $500 \mathrm{mg}$ de vitamina $C$ en el tercer trimestre de gestación, pudo observarse que la relación de TBARS/colesterol y TBARS/vitamina E estuvieron más elevados en el grupo 
de madres que recibió la suplementación con hierro + vitamina C que el grupo control (19). Así mismo, se ha observado que la vitamina $C$ puede movilizar apreciables cantidades de hierro de los depósitos y, en consecuencia, superar la capacidad de las proteínas que ligan hierro, produciéndose de esta manera hierro libre, que puede incrementar la generación de radicales libres.

Los resultados experimentales que se han mostrado en la presente investigación muestran inobjetablemente que el hierro del jarabe de sulfato ferroso reacciona con la vitamina $\mathrm{C}$ y genera radicales libres, así mismo, el comportamiento distinto del sulfato ferroso disuelto en agua destilada y el que se encuentra en el jarabe, indica la participación activa de los excipientes del jarabe en la reacción que se produce entre el ion ferroso y la vitamina C. Estos resultados sugieren que no debería recomendarse la ingesta de jugo de naranja o limonada, fuentes importantes de vitamina $\mathrm{C}$, para incrementar la absorción del hierro del jarabe de sulfato ferroso, por el probable daño que ejercería dicha asociación. Consideramos que es necesario desarrollar nuevas investigaciones para disponer de una mejor comprensión de los efectos adversos que podrían causar la administración de hierro no hemo y vitamina $C$ en pacientes anémicos.

\section{REFERENCIAS BIBLIOGRÁFICAS}

1. Instituto Nacional de Estadística e Informática Perú (INEI). Ficha técnica: Encuesta demográfica y de salud familiarENDES. 2016. Lima: INEI;2017

2. Knutson DM. Iron transport proteins: Gateways of cellular and systemic iron homeostasis. J Biol Chem. 2017;293(31):1273512743.

3. Lane DJR, Richardson DR. The active role of vitamin C in mammalian iron metabolism: Much more than just enhanced iron absorption!. Free Rad Biol Med. 2014;75:69-83

4. Fisher AEO, Naughton DP. Vitamin C contributes to inflammation via radical generating mechanisms: A cautionary note. Medical Hypotheses. 2003;61(5-6):657-660.

5. Guija E. Troncoso L. Radicales libres y envejecimiento. Bol Soc Quim Perú. 2000; LXVI:33-51.

6. Prousek J. Fenton chemistry in biology and medicine. Pure Appl. Chem. 2007;79(12):2325-2338.

7. Andrisica L, Dudzika D, Barbasa C, Milkovicb L, Grunec T, Zarkovicb N. Short overview on metabolomics approach to study pathophysiology of oxidative stress in cancer. Redox Biology. 2018;14:47-58.

8. Szeto YT, Chu WK, Benzie IFF. Antioxidants in fruits and vegetables: a study of cellular availability and direct effects on human DNA. Biosci Biotechnol Biochem. 2006;70(10): 2551-2555.

9. Buettner GR, Jurkiewicz BA. Catalytic Metals, Ascorbate and Free Radicals: Combinations to Avoid. Radiation Research. 1996; $145: 532-541$.

10. Gutteridge JMC. Ferrous-salt-promoted damage to deoxyribose and benzoate. Biochem J. 1987;243:709-714.

11. Buege JA, Aust SD. Microsomal lipid, Peroxidation. En: Flesicher S, Packer L. (Eds.), Methods in Enzymology Vol. 52. (Academic Press, New-York, 1978) pag. 302-310.

12. Gomberg M. An incidence of trivalent carbon trimetilfenil. J Am Chem Soc. 1900;22:757-771.

13. Gerschman R, Gilbert DL, Nye SW, Dwyer P, Fenn WO. Oxygen poisoning and $\mathrm{X}$-radiation. A mechanism in common. Science. 1954;119:623-626.

14. Harman D. Aging: a theory based on free radical and radiation chemistry. J Gerontol. 1956; 11(3): 298-300.

15. MC Cord JM, Fridovich I. Superoxide dismutase an enzymatic function for erythrocuprein (chemocuprein). J Biol Chem. 1969;244(22):6049-6055.

16. Lane DJR, Merlot AM, Huang ML, Bae D, Jansson PJ, Sahni $\mathrm{S}$, et al. Cellular iron uptake, trafficking and metabolism: Key molecules and mechanisms and their roles in desease. Biochim Biophs Acta. 2015;1853(5):1130-1144.

17. Herbert V, Shaw S, Jayatillekee E. Vitamin C-Driven Free Radical Generation from Iron. J Nutr. 1996;126(4S):1213S1220 S.

18. Fujimoto $Y$, Matsui M, Fujita T. The accumulation of ascorbic acid and iron in rat liver mitochondria after lipid peroxidation. Japan J Pharmacol. 1982;32(2):397-399.

19. Lachili B, Hininger I, Faure H, Arnaud J, Richard MJ, Favier A, et al. Increased lipid peroxidation in pregnant women after iron and vitamin C supplementation. Biol Trace Elem Res. 2001;83(2):103-110.

Fuentes de financiamiento:

Este artículo ha sido financiado por CONCYTEC mediante el proyecto $\mathrm{N}^{\circ} 145-2015$-Cienciactiva y por la Universidad de San Martín de Porres (E10012018018).

Conflictos de interés:

Los autores declaran no tener ningún conflicto de interés.

\section{Correspondencia:}

Henry Guija Guerra

Dirección: Av. Alameda del Corregidor 1531, Urb. Los Sirius, La Molina. Lima, Perú.

Teléfono: 981095856

Correo electrónico: hguijag@usmp.pe

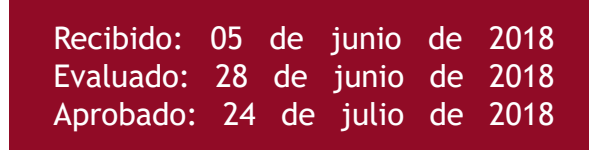

( $)$ La revista. Publicado por Universidad de San Martín de Porres, Perú. (cc) ${ }_{\text {Br }}$ Licencia de Creative Commons Artículo en acceso abierto bajo términos de Licencia Creative Commons Atribución 4.0 Internacional. (http://creativecommons.org/licenses/by/4.0/)

\section{ORCID iDs}

Henry Guija-Guerra

Emilio Guija-Poma

Jhon Ponce-Pardo

Miguel Inocente-Camones

Luis Camarena-Chaviguri https://orcid.org/0000-0002-0698-4464 https://orcid.org/0000-0002-2522-2772 https://orcid.org/0000-0001-9107-2752 https://orcid.org/0000-0003-0397-4356 https://orcid.org/0000-0001-5050-247X 